\title{
MICROWAVE-HYDROTHERMAL SYNTHESIS AND PHOTOCATALYTIC PROPERTIES OF Cr-DOPED $\mathrm{SrTiO}_{3}$ POWDERS
}

\author{
"RIGOBERTO LÓPEZ-JUÁREZ*, TERESITA J. PÉREZ-JUÁCHE*, ORLANDO HERNÁNDEZ-CRISTOBAL**, \\ NEFTALÍ RAZO-PÉREZ**, SANDRA CIPAGAUTA*** \\ *Unidad Morelia del Instituto de Investigaciones en Materiales, Universidad Nacional Autónoma de México, \\ Antigua Carretera a Pátzcuaro No. 8701, Col. Ex Hacienda de San José de la Huerta, \\ C.P. 58190, Morelia, Michoacán, México \\ **Escuela Nacional de Estudios Superiores, Universidad Nacional Autónoma de México, \\ Antigua Carretera a Pátzcuaro No. 8701, Col. Ex Hacienda de San José de la Huerta, \\ C.P. 58190, Morelia, Michoacán, México \\ ***Departamento de Química, Universidad Autónoma Metropolitana-Iztapalapa, \\ Av. San Rafael Atlixco No 186, Col. Vicentina, México 09340, D.F. México \\ "E-mail: rlopez@iim.unam.mx
}

Submitted September 29, 2020; accepted February 1, 2021

Keywords: Photocatalysts, X-ray diffraction, Nanopowders

\begin{abstract}
The synthesis of $\mathrm{Cr}$-doped $\mathrm{SrTiO}_{3}(x=0,0.02,0.04$ and 0.1) was performed by the microwave-hydrothermal method. The fast synthesis of $\mathrm{SrTi}_{0.96} \mathrm{Cr}_{0.04} \mathrm{O}_{3}$ pure phase powders was achieved at $200{ }^{\circ} \mathrm{C}$ for $30 \mathrm{~min}$. It was observed that chromium entered into the solid solution within the $\mathrm{SrTiO}_{3}$ lattice as was demonstrated from the XRD and Raman analyses. The mean crystal size of the synthesised powders was close to $60 \mathrm{~nm}$ as determined by XRD analysis and confirmed by the TEM images. The specific surface was measured and the values range from $27 \pm 2.8$ to $37 \pm 3.7 \mathrm{~m}^{2} \cdot \mathrm{g}^{-1}$. The photocatalytic properties were evaluated for the hydrogen evolution from the methanol solution. The best performance was observed for $x=0.04$, for which one of the highest surface areas was obtained $\left(34 \mathrm{~m}^{2} \cdot \mathrm{g}^{-1}\right)$ among the investigated compositions.
\end{abstract}

\section{INTRODUCTION}

Research on photocatalytic materials for water splitting and wastewater remediation has increased due to environmental concerns. The production of clean energy is being urged to cover the increasing energy demand and to avoid the use of fossil fuels that produce toxic gases during its burning. On the other hand, to achieve this goal, it is desirable to develop materials that can use sunlight (visible spectra) for this purpose, as it is an inexpensive and clean energy source. Among the prospect materials which can fulfil most of the requirements for water splitting are some semiconductor ceramics with a perovskite structure [1-2]. One of these materials is strontium titanate $\left(\mathrm{SrTiO}_{3}\right.$ or STO) that is known to possess a photocatalytic activity [3-5]. Unfortunately, STO has a wide bandgap $(\sim 3.2 \mathrm{eV})$, so that it is only active under UV-light irradiation. Then, in order to develop materials active under visible light irradiation, metal cations have been introduced into the STO lattice, lowering the absorption edge to the visible light region (red shifting). The majority of the research has been conducted using transition metal cations, noble metal cations and some non-metal anions [6-10]. The results have shown a reduction in the bandgap and an increase in the photocatalytic response. In addition to the doping strategy for enhancing the catalytic response, crystal size and morphology have also been modified in an attempt to improve the photocatalytic performance of STO. To achieve these modifications on the STO features, several synthesis methods have been tested, including a solidstate reaction [3, 11-12], sol-gel [13-14], Pechini [6, 15], conventional hydrothermal [16-17], solvothermal [4, 18-19], electrospinning [20], microwave-hydrothermal [21-22] and flux methods [23]. Most of these techniques require high temperatures or a long heat treatment time for the powder crystallisation. The microwave-hydrothermal method has recently gained popularity due to the low temperature required, fast synthesis time and the possibility to manipulate the crystal size and shape of the prepared powders [21-22, 24-25], along with the high purity in the produced materials. As a result, the properties of the synthesised powders can be manipulated according to the desired features.

In this work, $\mathrm{SrTi}_{1-x} \mathrm{Cr}_{x} \mathrm{O}_{3}(x=0,0.02,0.04$ and 0.1 ) powders were synthesised by the microwave-hydrothermal method and their photocatalytic properties were evaluated in the $\mathrm{H}_{2}$ evolution. 


\section{EXPERIMENTAL}

Synthesis of powders

For the synthesis of the STO and Cr-doped STO ceramics $\left(\mathrm{SrTi}_{1-x} \mathrm{Cr}_{\mathrm{x}} \mathrm{O}_{3}, x=0,0.02,0.04\right.$ and 0.1) Titanium isopropoxide (Ti $\left[\mathrm{OCH}\left(\mathrm{CH}_{3}\right)_{2}\right]_{4}$, Sigma-Aldrich $97 \%$ ), Strontium nitrate $\left(\mathrm{Sr}\left(\mathrm{NO}_{3}\right)_{2}\right.$, Sigma-Aldrich $\left.99 \%\right)$, Chromium(III) nitrate nonahydrate $\left(\mathrm{Sr}\left(\mathrm{NO}_{3}\right)_{3}-9 \mathrm{H}_{2} \mathrm{O}\right.$, SigmaAldrich $99 \%$ ), Potassium hydroxide ( $\mathrm{KOH}, 2 \mathrm{M})$, Isopropanol (JT Baker) and deionised water were used as the starting reagents. In a typical experiment, strontium and chromium nitrates were weighed according to the desired composition, and added into the reaction vessel followed by the addition of $8 \mathrm{ml}$ of isopropanol under constant stirring. Then titanium isopropoxide was added and stirred for $15 \mathrm{~min}$. Afterwards, $7 \mathrm{ml}$ of deionised water were mixed with the original solution producing a gel, to which $10 \mathrm{ml}$ of $\mathrm{KOH} 2 \mathrm{M}$ were added, and the resultant suspension was stirred for 15 minutes. The final mixture was sealed in a Teflon lined autoclave and heat treated at $200{ }^{\circ} \mathrm{C}$ for 60 minutes. To further investigate the possibility of reducing the synthesis time of the pure crystalline powders, experiments were conducted at 30 minutes for the composition of $x=0.04$. After the reaction time, the resultant precipitate was filtered, washed three times with deionised water and dried at $120{ }^{\circ} \mathrm{C}$ for $3 \mathrm{~h}$.

\section{Structural and microstructural characterisation}

The crystal structure was determined by X-ray powder diffraction (XRD) with a D2-Phaser diffractometer (Bruker) using $\mathrm{Cu} \mathrm{K} \alpha\left(\lambda_{I}=1.5406 \AA, \lambda_{2}=1.5444 \AA, \lambda_{2} / \lambda_{I}\right.$ ratio $=0.5$ ) radiation. The data were acquired from $15^{\circ}$ to $100^{\circ}$ in the $2 \theta$ range. Evaluation software of the XRD patterns (EVA, Bruker) was used for the crystal mean size calculation. The powder morphology was observed by scanning electron microscopy (SEM) with a JEOL JSM IT300 microscope, also, transmission electron microscopy (TEM) was used to observe the features of the crystals (JEOL JEM ARM200F). The chemical composition analyses were performed with the Energy Dispersive X-Ray Analysis (EDX) methodology with 5 minutes of exposition to ensure good statistics.

Raman spectroscopy can be used to monitor changes in the lattice response to doping. Then, the Raman analysis was performed with Bruker Senterra II equipment $(\lambda=$ $532 \mathrm{~nm}, 5 \mathrm{~mW}$ ) from 50 to $1200 \mathrm{~cm}^{-1}$.

\section{Optical absorption and band gap calculation}

The absorption spectra were obtained by using the diffuse reflectance technique. The measurements were performed in a Cary 5 spectrophotometer equipped with a Praying Mantis (Harrick Scientific Products, Inc.) accessory for the diffuse reflection spectroscopy. The spectra were recorded in the wavelength range between 200 and $800 \mathrm{~nm}$. The band gaps were estimated from the absorption spectra following the procedure described elsewhere [16].

\section{Specific surface area and photocatalytic performance}

In order to measure the specific surface area, the Brunauer-Emmett-Teller (BET) method was used with Quantachrome Autosorb 3B equipment. Before the surface analysis, the samples were heated at $250{ }^{\circ} \mathrm{C}$ for $5 \mathrm{~h}$ for degasification.

The photocatalytic performance was evaluated by quantifying the $\mathrm{H}_{2}$ evolution. In a typical experiment, 50 milligrams of powder were loaded into a water-methanol solution (1:1 ratio). To ensure the adsorption-desorption equilibrium, the system was stirred in the dark for $15 \mathrm{~min}$ and degassed by bubbling nitrogen, prior to the photochemical reaction test. The water splitting reaction was undertaken in a quartz closed reactor cell coupled with a gas chromatograph (Shimadzu G-08) equipped with a thermal conductivity detector (TCD) and a Shincarbon packed column (2 m length, $1 \mathrm{~mm}$

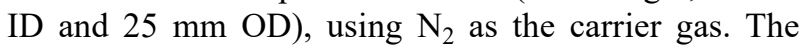
amount of evolved $\mathrm{H}_{2}$ was measured at time intervals of $1 \mathrm{~h}$ for a time period of $5 \mathrm{~h}$. The experiments were performed with UV radiation $(254 \mathrm{~nm})$ produced by a high-pressure mercury lamp (Pen-Ray Mercury Lamp with $I_{0}=2 \mathrm{~mW} \cdot \mathrm{cm}^{-2}$ ) and without any loaded cocatalyst.

\section{RESULTS AND DISCUSSION}

In Figure 1, the XRD patterns of the undoped and $\mathrm{Cr}$-doped $\mathrm{SrTiO}_{3}$ powders are shown. For all the compositions, a pure phase is observed when the samples were synthesised at $200{ }^{\circ} \mathrm{C}$ for $60 \mathrm{~min}$. The $\mathrm{SrTi}_{0.96} \mathrm{Cr}_{0.04} \mathrm{O}_{3}$ composition was also prepared reducing the synthesis time to $30 \mathrm{~min}$. The results presented in Figure $1 \mathrm{~b}$ also suggest that the pure phase was observed for samples obtained under a reduced synthesis time. This could be achieved due to the high energy input using the microwave-hydrothermal method (MHM). The activation energy does not change when a reaction takes place, but using the MHM, the energy input rate is increased, which makes the high synthesis rate of materials possible [24]. The fast synthesis of other materials has been reported by the MHM including $\mathrm{NaNbO}_{3}, \mathrm{~K}_{0.5} \mathrm{Na}_{0.5} \mathrm{NbO}_{3}, \mathrm{BiFeO}_{3}$ and $\mathrm{KNbO}_{3}$ [25-27].

On the other hand, the preparation of $\mathrm{SrTiO}_{3}$ has been reported using conventional hydrothermal methods with a reaction time exceeding $7 \mathrm{~h}$ [16]. While $\mathrm{Cr}-\mathrm{La}-$ doped $\mathrm{SrTiO}_{3}$ materials have been synthesised by the MHM method, with a synthesis time of $90 \mathrm{~min}$ [22]. Moreover, the solvothermal method has been used for the preparation of $\mathrm{Cr}$-doped $\mathrm{SrTiO}_{3}$, but with a longer synthesis time and an additional calcination treatment [4]. 


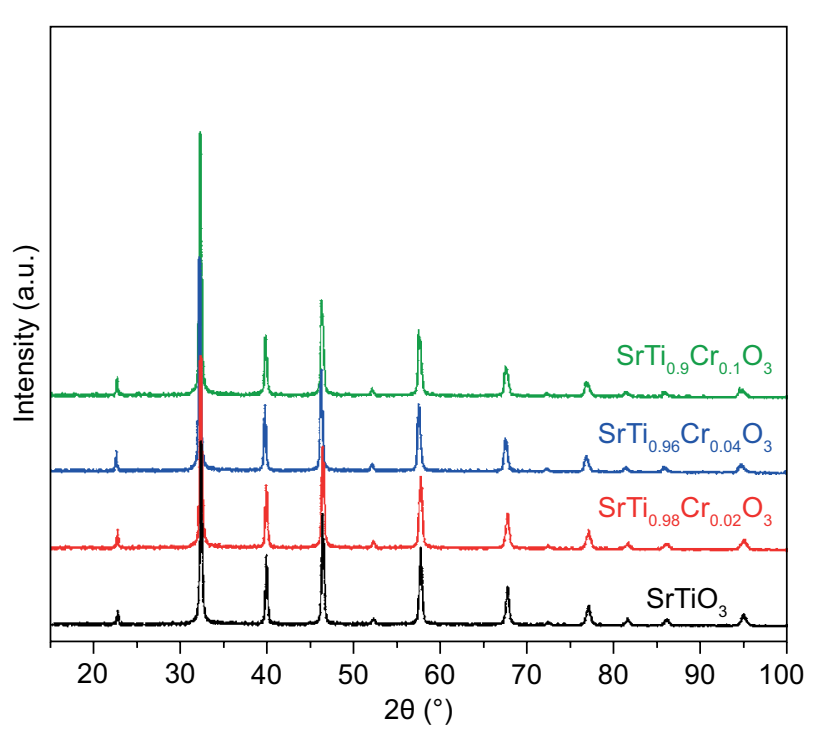

a)

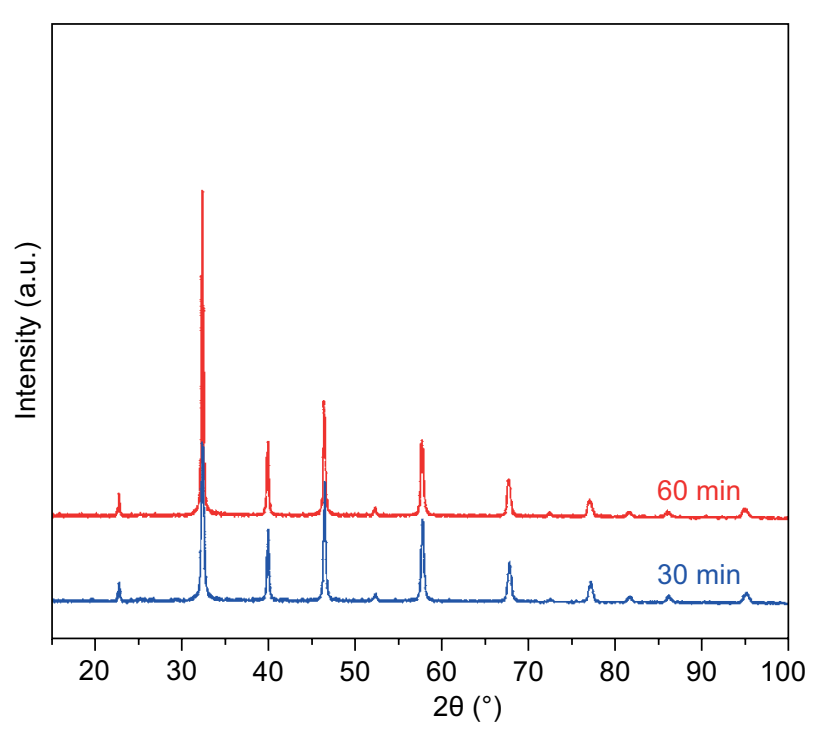

b)

Figure 1. XRD patterns of the undoped and Cr-doped $\mathrm{SrTiO}_{3}$ powders synthesised under different conditions: a) at $200{ }^{\circ} \mathrm{C}$ and 60 min, b) $\mathrm{SrTi}_{0.96} \mathrm{Cr}_{0.04} \mathrm{O}_{3}$ at $200{ }^{\circ} \mathrm{C}$ for different times.

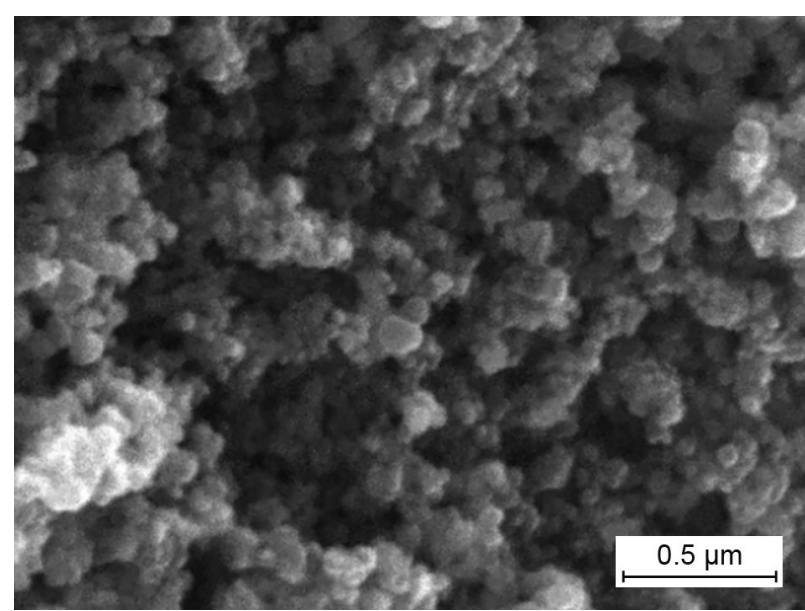

a) $\mathrm{SrTiO}_{3}$

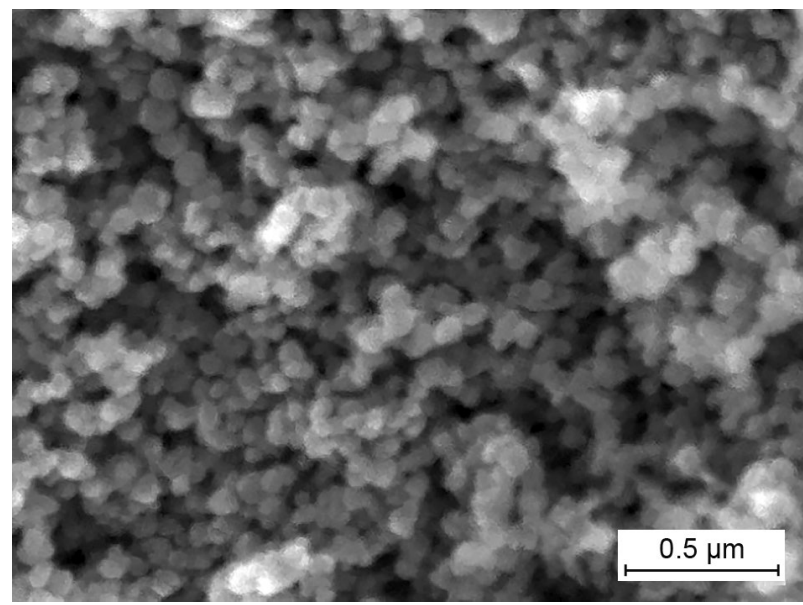

c) $\mathrm{SrTi}_{0.96} \mathrm{Cr}_{0.04} \mathrm{O}_{3}$

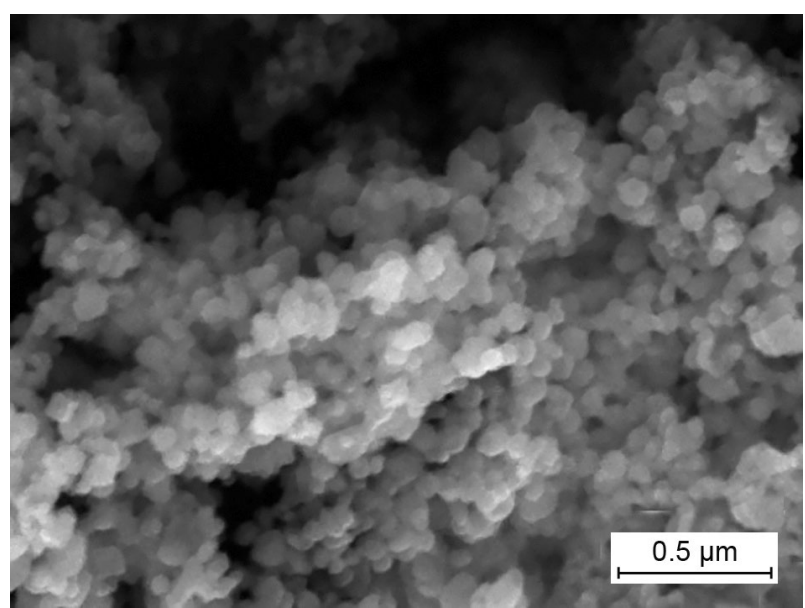

b) $\mathrm{SrTi}_{0.98} \mathrm{Cr}_{0.02} \mathrm{O}_{3}$

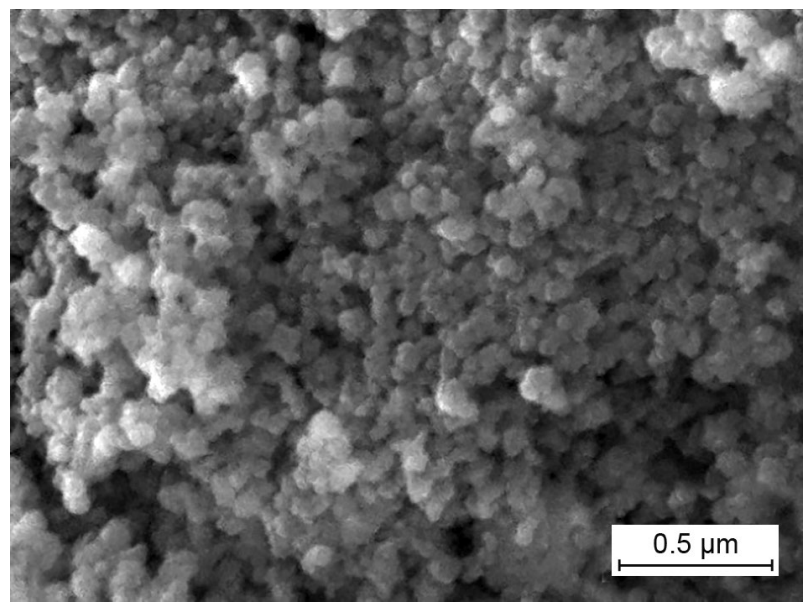

d) $\mathrm{SrTi}_{0.9} \mathrm{Cr}_{0.1} \mathrm{O}_{3}$

Figure 2. SEM images of the undoped and $\mathrm{Cr}$-doped $\mathrm{SrTiO}_{3}$ powders synthesised at $200{ }^{\circ} \mathrm{C}$ and $\left.\left.60 \mathrm{~min}: \mathrm{a}\right) \mathrm{SrTiO}_{3}, \mathrm{~b}\right) \mathrm{SrTi}_{0.98} \mathrm{Cr}_{0.02} \mathrm{O}_{3}$, c) $\mathrm{SrTi}_{0.96} \mathrm{Cr}_{0.04} \mathrm{O}_{3}$ and d) $\mathrm{SrTi}_{0.9} \mathrm{Cr}_{0.1} \mathrm{O}_{3}$. 
From the SEM images shown in Figure 2, it is possible to observe that all the samples are composed of nanometric crystals. This feature would have a positive effect on the photocatalytic performance, because the distance for the electron-hole pair migration path is reduced. Furthermore, the specific surface area is high in nanometric powders which increase the reaction sites [28]. Regarding the average crystal size obtained in Cr-doped STO powders, the measured values using the XRD results were: $57.1 \pm 1.0,41.0 \pm 0.8,41.5 \pm 0.8$, $37.5 \pm 0.4$, for $x=0,0.02,0.04$ and 0.1 , respectively. Similar results, with values close to $30 \mathrm{~nm}$, were obtained for related compositions using the conventional hydrothermal method plus calcination [17] and the microwave-hydrothermal technique [22]. The TEM images of the $\mathrm{SrTi}_{0.96} \mathrm{Cr}_{0.04} \mathrm{O}_{3}$ sample synthesised at $200{ }^{\circ} \mathrm{C}$ for 60 min can be observed in Figure 3. For the better resolution of the powder morphology, the bright and scanning transmission electron microscopy (STEM) modes were used. From these images, the cubic-like morphology of the prepared powders is clearly observed. This and other images were used to measure the mean crystal

Table 1 . Chemical analysis by EDS of the undoped and $10 \mathrm{~mol} . \%$ Cr-doped powders.

\begin{tabular}{ccc}
\hline Composition & $0 \%$ & $10 \%$ \\
\hline Element & Atomic \% & Atomic \% \\
\hline $\mathrm{O}$ & $66.65 \pm 0.61$ & $68.99 \pm 0.60$ \\
$\mathrm{Sr}$ & $17.90 \pm 0.08$ & $15.02 \pm 0.06$ \\
$\mathrm{Ti}$ & $15.44 \pm 0.12$ & $14.57 \pm 0.06$ \\
$\mathrm{Cr}$ & 0 & $1.42 \pm 0.06$ \\
Total: & 100.00 & 100.00 \\
\hline
\end{tabular}

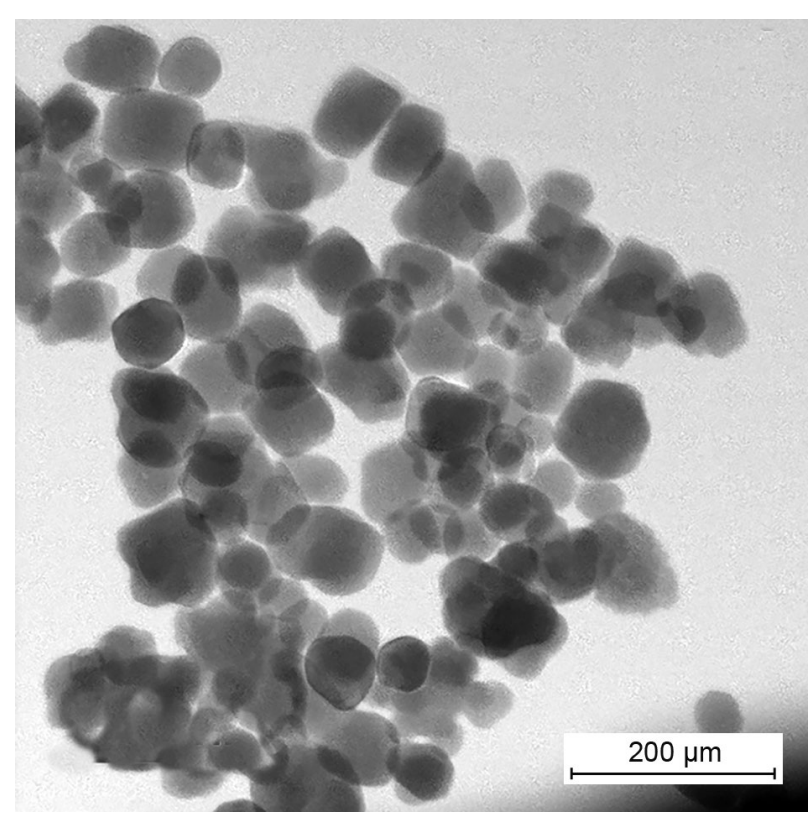

a) Bright field size of $62 \mathrm{~nm} \pm 11 \mathrm{~nm}$, which, for this purpose, around 130 crystals were considered. This experimental value agrees with the results obtained from the XRD analysis (considering the error in the measurement) and the SEM images presented above.

In Table 1 the energy-dispersive X-ray spectrometry (EDS) analyses for the undoped and $x=0.1$ compositions are presented. Both analyses demonstrate that the pure phase is obtained in the Cr-doped STO powders. The results are practically the nominal compositions considering the errors ascribed to the technique, and those results are reliable enough due to the new technology development for the EDS measurements [29-30].

The results for the band gap measurement are shown in Figure 4 and summarised in Table 2. From these data, band gap values between 3.28 and $2.18 \mathrm{eV}$ were obtained for the undoped and Cr-doped STO powders. These values are comparable with those reported in literature for similar compositions [16,19,20,22,31]. For example, Sulaeman et al. [19] reported band gap values for $x=0$ and $x=0.02$ of 3.18 and $\sim 2.2 \mathrm{eV}$, respectively, while Akita et al. [22] reported for $x=0$ and $x=0.3(\mathrm{Cr}-\mathrm{La}$ co-doped STO) band gaps of $3.28 \mathrm{eV}$ and $2.35 \mathrm{eV}$, respectively.

Table 2. Band gap of the Cr-doped powders.

\begin{tabular}{lc}
\hline Sample & Band gap \\
\hline $\mathrm{SrTiO}_{3}-200{ }^{\circ} \mathrm{C} / 60 \mathrm{~min}$ & $3.28 \mathrm{eV}$ \\
$\mathrm{SrTi}_{0.98} \mathrm{Cr}_{0.02} \mathrm{O}_{3}-200{ }^{\circ} \mathrm{C} / 60 \mathrm{~min}$ & $2.48 \mathrm{eV}$ \\
$\mathrm{SrTi}_{0.96} \mathrm{Cr}_{0.04} \mathrm{O}_{3}-200^{\circ} \mathrm{C} / 60 \mathrm{~min}$ & $2.40 \mathrm{eV}$ \\
$\mathrm{SrTi}_{0.9} \mathrm{Cr}_{0.1} \mathrm{O}_{3}-200{ }^{\circ} \mathrm{C} / 60 \mathrm{~min}$ & $2.37 \mathrm{eV}$ \\
$\mathrm{SrTi}_{0.96} \mathrm{Cr}_{0.04} \mathrm{O}_{3}-200{ }^{\circ} \mathrm{C} / 30 \mathrm{~min}$ & $2.40 \mathrm{eV}$ \\
$\mathrm{SrTi}_{0.96} \mathrm{Cr}_{0.04} \mathrm{O}_{3}-180^{\circ} \mathrm{C} / 30 \mathrm{~min}$ & $2.18 \mathrm{eV}$ \\
\hline
\end{tabular}

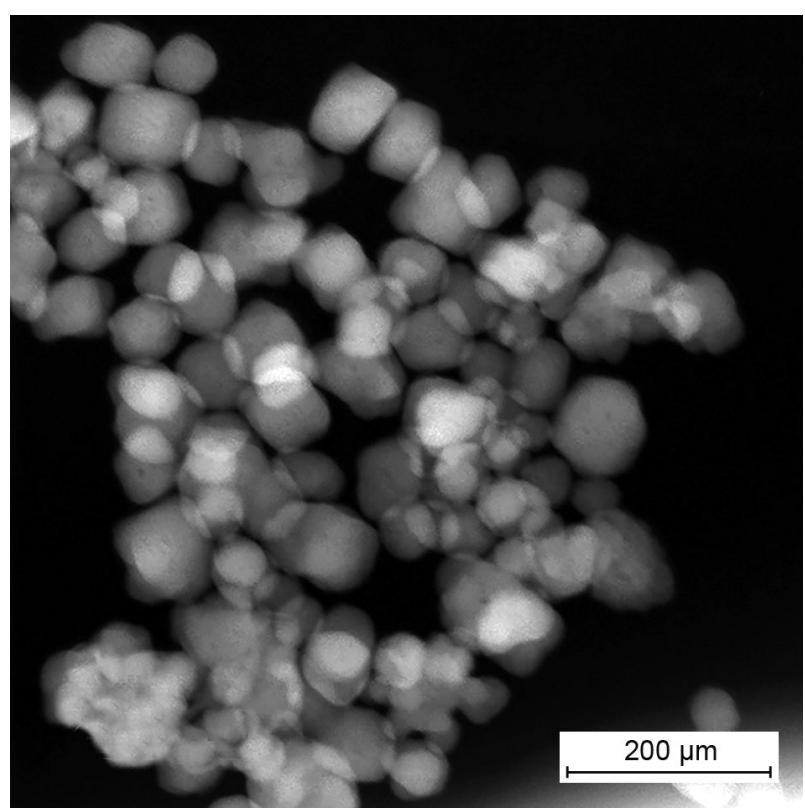

b) STEM

Figure 3. STEM images of the $\mathrm{SrTi}_{0.96} \mathrm{Cr}_{0.04} \mathrm{O}_{3}$ sample synthesised at $200{ }^{\circ} \mathrm{C}$ for $60 \mathrm{~min}$ with the microwave-hydrothermal method: a) Bright field and b) STEM. 


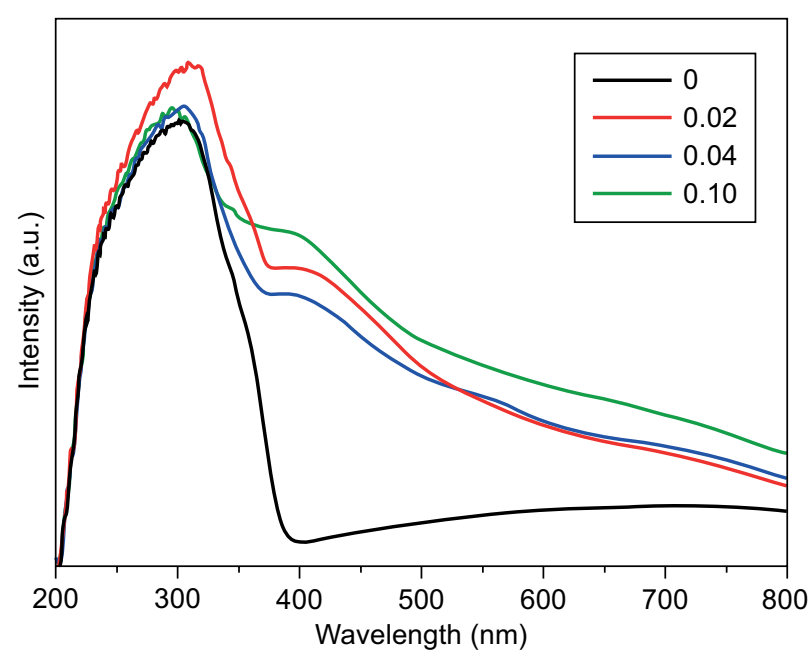

Figure 4. Diffuse reflectance spectra for the Cr-doped powders synthesised at $200{ }^{\circ} \mathrm{C}$ and $60 \mathrm{~min}$.

The addition of chromium has promoted a decrease in the band gap due to the intermediate electronic levels introduced. This is clearly evident because the colour of the powders has changed from white for the STO to darkgreen for the $\mathrm{Cr}$-doped samples. From the UV-vis graph, it is evident that the band gap has shifted to the visible region. The absorption edge has changed from near $400 \mathrm{~nm}$ to $450-490 \mathrm{~nm}$, corresponding to the undoped and $\mathrm{Cr}$-doped samples. The absorption band that appears close to $460-500 \mathrm{~nm}$ is ascribed to the $\mathrm{Cr}^{3+}-\mathrm{Ti}^{4+}$ charge transfer. The intermediate level introduced by the $\mathrm{Cr}^{3+}$. doping produces a hybridisation in the conduction band that is constructed by the $\mathrm{Ti}^{4+} 3 d$ and $\mathrm{Cr}^{3+} 3 d$ orbitals [22,31].

The Raman spectroscopy results are presented in Figure 5. For the undoped sample, the spectra have several vibrations signals, ranging from 80 to $1024 \mathrm{~cm}^{-1}$. These results agree with previous reports for the undoped STO [21,32]. The broad anomalies close to 300 and
$700 \mathrm{~cm}^{-1}$ correspond to first and second order vibrations [32]. This means that there are local compositional fluctuations that represent a phase transition to a polar phase. Furthermore, the $770 \mathrm{~cm}^{-1}$ signal is ascribed to the disorder due to the addition of $\mathrm{Cr}^{3+}$ cation [32], which is why it is not seen for the undoped sample. Moreover, this signal becomes broader and shifts slightly to a higher wavenumber with the increasing $\mathrm{Cr}^{3+}$ doping (Figure 5b). Furthermore, the 175 and $275 \mathrm{~cm}^{-1}$ anomalies are ascribed to the $\mathrm{O}-\mathrm{Sr}-\mathrm{O}$ bending modes, while that one at $545 \mathrm{~cm}^{-1}$ is assigned to the Ti-O-Ti bending mode [21]. Then, the Raman spectroscopy is capable of sensing the doping in solid solutions.

According to the above results, the purity, crystal size and band gap requirements for adequate water splitting are fulfilled. Then a high photocatalytic activity is expected for powders synthesised by the microwavehydrothermal method.

The specific surface area and photocatalytic performance for the hydrogen production are shown in Table 3. Generally speaking, the specific surface area increases slightly with the Cr-doping, and the highest value is reported for $x=0.1$ which agrees with the decreasing trend in the measured average crystal size.

Regarding the photocatalytic properties, the hydrogen production also increases with the Cr-doping. As stated above, the band gap has been reduced due to the intermediate electronic levels introduced by the chromium, and, as a result, the hydrogen production has increased. Furthermore, the increase in the surface area also may have influenced the $\mathrm{H}_{2}$ evolution. The catalytic performance depends upon parameters such as the surface area, band gap, and crystallinity [31]. Then, considering these issues, it is observed that specific surface area has played an important role in increasing the $\mathrm{H}_{2}$ generation, because the band gap values are similar for most $\mathrm{Cr}$-doped $\mathrm{SrTiO}_{3}$ synthesised compositions and

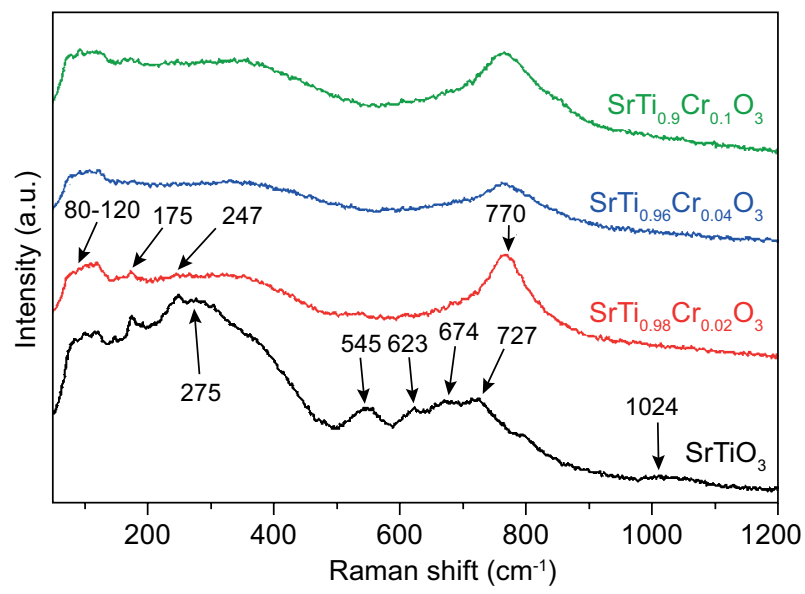

a)

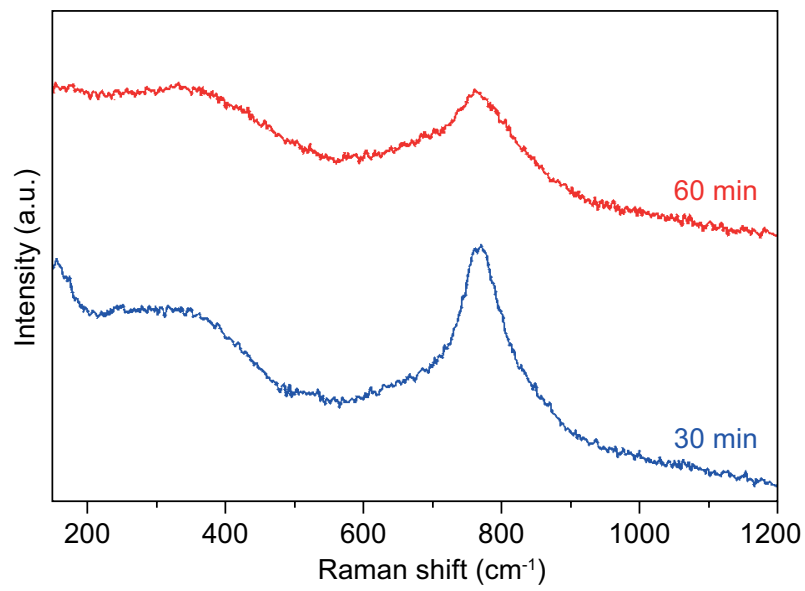

b)

Figure 5. Raman spectra of the $\mathrm{Cr}$-doped powders synthesised at: $200{ }^{\circ} \mathrm{C}$ and $60 \mathrm{~min}$ and b) $\mathrm{SrTi}_{0.96} \mathrm{Cr}_{0.04} \mathrm{O}_{3}$ at $200{ }^{\circ} \mathrm{C}$ and different times. 
López-Juárez R., Pérez-Juáche T. J., Hernández-Cristobal O., Razo-Pérez N., Cipagauta S.

Table 3. Photocatalytic activity of the Cr-doped powders.

\begin{tabular}{lcc}
\hline Sample & $\begin{array}{c}\text { Specific surface area } \\
\left(\mathrm{m}^{2} \cdot \mathrm{g}^{-1}\right)\end{array}$ & $\begin{array}{c}\mathrm{H}_{2} \text { production } \\
\left(\mu \mathrm{mol}^{-1} \cdot \mathrm{h}^{-1} \cdot \mathrm{g}_{\text {cat }}{ }^{-1}\right)\end{array}$ \\
\hline $\mathrm{SrTiO}_{3}-200{ }^{\circ} \mathrm{C} / 60 \mathrm{~min}$ & $27 \pm 2.8$ & $438 \pm 21$ \\
$\mathrm{SrTi}_{0.98} \mathrm{Cr}_{0.02} \mathrm{O}_{3}-200{ }^{\circ} \mathrm{C} / 60 \mathrm{~min}$ & $27 \pm 2.8$ & $498 \pm 24$ \\
$\mathrm{SrTi}_{0.96} \mathrm{Cr}_{0.04} \mathrm{O}_{3}-200^{\circ} \mathrm{C} / 60 \mathrm{~min}$ & $28 \pm 2.9$ & $409 \pm 20$ \\
$\mathrm{SrTi}_{0.9} \mathrm{Cr}_{0.1} \mathrm{O}_{3}-200{ }^{\circ} \mathrm{C} / 60 \mathrm{~min}$ & $37 \pm 3.7$ & $408 \pm 19$ \\
$\mathrm{SrTi}_{0.96} \mathrm{Cr}_{0.04} \mathrm{O}_{3}-200^{\circ} \mathrm{C} / 30 \mathrm{~min}$ & $34 \pm 3.5$ & $504 \pm 25$ \\
$\mathrm{SrTi}_{0.96} \mathrm{Cr}_{0.04} \mathrm{O}_{3}-180^{\circ} \mathrm{C} / 30 \mathrm{~min}$ & $33 \pm 3.4$ & $483 \pm 24$ \\
\hline
\end{tabular}

the heat treatment was similar. Furthermore, this could explain some of the results in Table 3. For example, samples with $x=0.02$ synthesised for $60 \mathrm{~min}$ has a similar photocatalytic performance to the sample with $x=0.04$ processed during $30 \mathrm{~min}$. In these two samples, as the reaction time is reduced, a smaller crystal size is observed and a higher surface area is obtained, which benefits the photocatalytic activity [6]. The sample with $x=0.1$ presents the highest surface area among the prepared samples, but the activity is the lowest, this could be related to an increase in the dopant concentration that increases the defects (vacancies and lattice distortions), which function as electron-hole recombination centres [20].

On the other hand, the $\mathrm{H}_{2}$ evolution reported in this work is higher compared with previous reports [19,31]. This could be explained by the low synthesis temperature, higher crystallinity and high surface area obtained in the Cr-doped STO by the microwave-hydrothermal method.

In relation to the $\mathrm{H}_{2}$ evolution, this increases with time and this performance was stable during the $5 \mathrm{~h}$ that the experiments lasted. Moreover, the powders maintained their structural stability during the measurements.

\section{CONCLUSIONS}

Pure phase Cr-doped $\mathrm{SrTiO}_{3}$ powders were synthesised by the microwave-hydrothermal assisted method under reduced time conditions. The crystal mean size for the different compositions measured from the XRD patterns ranged from $37.5 \pm 0.4$ to $57.1 \pm 1.0 \mathrm{~nm}$. The band gap was effectively reduced from $3.28 \mathrm{eV}$ for the undoped $\mathrm{SrTiO}_{3}$ to $2.36 \mathrm{eV}$ for $x=0.1$. A high surface area was obtained in the crystalline powders, with the highest values for $x=0.1$. A good $\mathrm{H}_{2}$ evolution was measured for all the samples, with a higher activity observed for the $\mathrm{SrTi}_{0.96} \mathrm{Cr}_{0.04} \mathrm{O}_{3}$ composition. It was observed that a combination of energy levels was introduced by the Cr-doping (diminishing band gap), as well as the increasing the surface area (short reaction time that produce nanometric powders) plays a crucial role in order to enhance the $\mathrm{H}_{2}$ evolution using $\mathrm{Cr}$-doped $\mathrm{SrTiO}_{3}$ materials.

\section{Acknowledgements}

The authors want to thank to UNAM-DGAPA for the financial support for carrying out the present research under project number PAPIIT-IN101518.

\section{REFERENCES}

1. Kanhere P., Chen Z. (2014): A Review on Visible Light Active Perovskite-Based Photocatalysts. Molecules, 19, 19995-20022. doi: 10.3390/molecules 191219995

2. Shi J., Guo L. (2012): $\mathrm{ABO}_{3}$-based photocatalysts for water splitting. Progress in Natural Science: Materials International, 22, 592-615. doi: 10.1016/j.pnsc.2012.12. 002

3. Kato H., Kudo A. (2002): Visible-Light-Response and Photocatalytic Activities of $\mathrm{TiO}_{2}$ and $\mathrm{SrTiO}_{3}$ Photocatalysts Codoped with Antimony and Chromium. Journal of Physical Chemistry B, 106, 5029-5034. doi: 10.1021/ jp0255482

4. Shi J., Shen S., Chen Y., Guo L., Mao S. S. (2012): Visible light-driven photocatalysis of doped $\mathrm{SrTiO}_{3}$ tubular structure. Optics Express, 20, A351-A359. doi: 10.1364/OE.20. 00A351

5. Rechberger F., Ilari G., Willa C., Tervoort E., Niederberger M. (2017): Processing of Cr doped $\mathrm{SrTiO}_{3}$ nanoparticles into high surface area aerogels and thin films. Materials Chemistry Frontiers, 1, 1662-1667. doi: 10.1039/C7QM00155J

6. Tonda S., Kumar S., Anjaneyulu O., Shanker V. (2014): Synthesis of $\mathrm{Cr}$ and La-codoped $\mathrm{SrTiO}_{3}$ nanoparticles for enhanced photocatalytic performance under sunlight irradiation. Physical Chemistry Chemical Physics, 16, 23819-23828. doi: 10.1039/C4CP02963A

7. Kato H., Sasaki Y., Shirakura N., Kudo A. (2013): Synthesis of highly active rhodium-doped $\mathrm{SrTiO}_{3}$ powders in $\mathrm{Z}$-scheme systems for visible-light-driven photocatalytic overall water splitting. Journal of Materials Chemistry A, 1, 12327-12333. doi: 10.1039/C3TA12803B

8. Modak B., Srinivasu K. Ghosh S. K. (2014): Improving photocatalytic properties of $\mathrm{SrTiO}_{3}$ through $(\mathrm{Sb}, \mathrm{N})$ codoping: a hybrid density functional study. RSC Advances, 4, 45703-45709. doi: 10.1039/C4RA07289H

9. Niishiro R., Kudo A. (2010): Development of visible-lightdriven $\mathrm{TiO}_{2}$ and $\mathrm{SrTiO}_{3}$ photocatalysts doped with metal cations for $\mathrm{H}_{2}$ or $\mathrm{O}_{2}$ evolution. Solid State Phenomena, 162, 29-40. doi: 10.4028/www.scientific.net/SSP.162.29

10. Kudo A., Miseki Y. (2009): Heterogeneous photocatalyst materials for water splitting. Chemical Society Reviews, 38, 253-278. doi: 10.1039/B800489G 
11. Chavesa A. S., Raponib O. A., Gelfuso M. V. (2015): Pure and $\mathrm{La}^{3+} / \mathrm{Nd}^{3+}$ Doped $\mathrm{SrTiO}_{3}$ Powders Obtained by Solid State Reaction and Microwave Assisted Hydrothermal Synthesis. Materials Science Forum, 820, 167-171. doi: 10.4028/www.scientific.net/MSF.820.167

12. Viruthagiri G., Praveen P., Mugundan S., Gopinathan E. (2013): Synthesis and Characterization of Pure and Nickel Doped $\mathrm{SrTiO}_{3}$ Nanoparticles via Soli State Reaction Route. Indian Journal of Advances in Chemical Science, 1, 132-138.

13. Thampi K. R., Rao M. S., Schwarz W., Gratzel M., Kiwi J. (1988): Preparation of $\mathrm{SrTiO}_{3}$ by Sol-Gel Techniques for the Photoinduced Production of $\mathrm{H}_{2}$, and Surface Peroxides from Water. Journal of the Chemical Society, Faraday Transactions, 84, 1703. doi: 10.1039/F19888401703

14. Zhang W., Du L., Ma Z., Bi F., He H. (2015): Sol-gel Preparation of $\mathrm{SrTiO}_{3}$ Photocatalyst Loaded on HZSM-5 Zeolite. Journal of Advanced Oxidation Technologies, 18, 376. doi: $10.1515 /$ jaots-2015-0226

15. Chang C.-H., Shen Y.-H. (2006): Synthesis and characterization of chromium doped $\mathrm{SrTiO}_{3}$ photocatalyst. Materials Letters, 60, 129-132. doi: 10.1016/j.matlet.2005.08.005

16. Kalyani V., Vasile B.S., Ianculescu A., Testino A., Carino A., Buscaglia M. T., Buscaglia V., Nanni P. (2015): Hydrothermal Synthesis of $\mathrm{SrTiO}_{3}$ : Role of Interfaces. Crystal Growth and Design, 15, 5712-5725. doi: 10.1021/acs.cgd. $5 \mathrm{~b} 00770$

17. Rahman Q. I., Ahmad M., Mehta S. K. (2017): Hydrothermal synthesis of $\mathrm{Cr}$-doped $\mathrm{SrTiO}_{3}$ nanoparticles for rhodamine-B dye degradation under visible light illumination. Colloid and Polymer Science, 295, 933-937. doi: 10.1007/ s00396-017-4085-x

18. Kimijima T., Kanie K., Nakaya M., Muramatsu A. (2014): Solvothermal synthesis of $\mathrm{SrTiO}_{3}$ nanoparticles precisely controlled in surface crystal planes and their photocatalytic activity. Applied Catalysis B: Environmental, 144, 462-467. doi: 10.1016/j.apcatb.2013.07.051

19. Sulaeman U., Yin S., Sato T. (2011): Solvothermal synthesis and photocatalytic properties of chromium-doped $\mathrm{SrTiO}_{3}$ nanoparticles. Applied Catalysis B: Environmental, 105, 206-210. doi: 10.1016/j.apcatb.2011.04.017

20. Hou D., Hu X., Ho W., Hu P., Huang Y. (2015): Facile fabrication of porous Cr-doped $\mathrm{SrTiO}_{3}$ nanotubes by electrospinning and their enhanced visible-light-driven photocatalytic properties. Journal of Materials Chemistry A, 3, 3935-3943. doi: 10.1039/C4TA05485G

21. da Silva L. F., Avansi Jr W., Andrés J., Ribeiro C., Moreira M. L., Longo E., Mastelaro V. R. (2013): Long-range and short-range structures of cube-like shape $\mathrm{SrTiO}_{3}$ powders: microwave-assisted hydrothermal synthesis and photocatalytic activity. Physical Chemistry Chemical Physics, 15, 12386-12393. doi: 10.1039/C3CP50643F
22. Akita R., Dong Q., Yin S., Sato T. (2014): Microwaveassisted Hydrothermal Synthesis and Photocatalytic Properties of $\mathrm{Cr}$ and La-codoped $\mathrm{SrTiO}_{3}$ Photocatalyst. Key Engineering Materials, 608, 147-152. doi: 10.4028/www. scientific.net/KEM.608.147

23. Ham Y., Hisatomi T., Goto Y., Moriya Y., Sakata Y., Yamakata A., Kubota J., Domen K. (2016): Flux-mediated doping of $\mathrm{SrTiO}_{3}$ photocatalysts for efficient overall water splitting. Journal of Materials Chemistry A, 4, 3027-3033. doi: 10.1039/C5TA04843E

24. Hayes B. L. (2002). Microwave synthesis: Chemistry at the Speed of Light. First edition, CEM Publishing. doi: 10. 5860/choice.40-4619

25. López-Juárez R., Castañeda-Guzmán R., Villafuerte-Castrejón M. E. (2014): Fast synthesis of $\mathrm{NaNbO}_{3}$ and $\mathrm{K}_{0.5} \mathrm{Na}_{0.5} \mathrm{NbO}_{3}$ by microwave hydrothermal method. Ceramics International, 40, 14757-14764. doi: 10.1016/j. ceramint.2014.06.065

26. Prado-Gonjal J., Villafuerte-Castrejón M. E., Fuentes L., Morán E. (2009): Microwave-hydrothermal synthesis of the multiferroic $\mathrm{BiFeO}_{3}$. Materials Research Bulletin, 44, 1734-1737. doi: 10.1016/j.materresbull.2009.03.015

27. Paula A. J., Parra R., Zaghete M. A., Varela J. A. (2008): Synthesis of $\mathrm{KNbO}_{3}$ nanostructures by a microwave assisted hydrothermal method. Materials Letters, 62, 2581-2584. doi:10.1016/j.matlet.2007.12.059

28. Yuan L., Han C., Yang M.-Q., Xu Y.-J. (2016): Photocatalytic water splitting for solar hydrogen generation: fundamentals and recent advancements. International Reviews in Physical Chemistry, 35, 1-36. doi: 10.1080/0144235X.2015.1127027

29. Miler M., Mirtič B. (2013): Accuracy and precision of EDS analysis for identification of metal-bearing minerals in polished and rough particle samples. Geologija, 56, 005-018. doi: 10.5474/geologija.2013.001

30. Newbury D. E., Ritchie N. W. M. (2015): Performing elemental microanalysis with high accuracy and high precision by scanning electron microscopy/silicon drift detector energy-dispersive X-ray spectrometry (SEM/SDD-EDS). Journal of Materials Science, 50, 493-518. doi: 10.1007/ s10853-014-8685-2

31. Liu J. W., Chen G., Li Z. H., Zhang Z. G. (2006): Electronic structure and visible light photocatalysis water splitting property of chromium-doped $\mathrm{SrTiO}_{3}$. Journal of Solid State Chemistry, 179, 3704-3708. doi: 10.1016/j.jssc.2006. 08.014

32. Muralidharan M., Anbarasu V., Perumal A. E., Sivakumar K. (2015): Carrier mediated ferromagnetism in $\mathrm{Cr}$ doped $\mathrm{SrTiO}_{3}$ compounds. Journal of Materials Science: Materials in Electronics, 26, 6352-6365. doi: 10.1007/s10854015-3223-9 